\title{
Overweight male personnel of the Japan Self-Defense Forces with body mass indices of 23.0-24.9 and obesity-related metabolic disorders
}

\author{
Hidenari Sakuta · Takashi Suzuki
}

Received: 15 June 2007 / Accepted: 9 October 2007 / Published online: 28 February 2008

(C) The Japanese Society for Hygiene 2008

\begin{abstract}
Objectives To assess the validity of the criterion of overweight for Asian people that is recommended by Western Pacific Region of the World Health Organization. Methods We carried out a cross-sectional analysis of the association between the criterion of overweight for ethnic Asian people-body mass indices (BMI) of $23.0-24.9 \mathrm{~kg} /$ $\mathrm{m}^{2}$-and the presence of obesity-related metabolic disorders among middle-aged Japanese men $(n=974$, age range 51-59).

Results The odds ratios (95\% confidence interval) of overweight to those with normal weight (BMI $<23.0 \mathrm{~kg}$ / $\mathrm{m}^{2}$ ) were $1.61(1.11-2.33)$ for the presence of impaired glucose tolerance, 1.95 (1.30-2.93) for hypertension, 2.22 (1.63-3.03) for hypercholesterolemia, 2.83 (2.02-3.97) for hypertriglyceridemia, and $2.06(1.06-4.00)$ for hyperuricemia. Overweight was not associated with the presence of type 2 diabetes or with high $\gamma$-glutamyl transrease in the present study (odds ratios: 1.09 and 1.05, respectively). Adjustment for age, rank, and lifestyle factors affected the results only slightly.
\end{abstract}

\section{H. Sakuta}

Department of Internal Medicine,

Self-Defense Forces Central Hospital,

Tokyo, Japan

\section{T. Suzuki}

Department of Research and Laboratory,

Self-Defense Forces Central Hospital,

Tokyo, Japan

\section{H. Sakuta $(\bowtie)$}

Department of Internal Medicine, Self-Defense Forces,

Sendai Hospital, 1-1 Minaminometate, Miyagino-ku,

Sendai 983-0041, Japan

e-mail: hsakuta@msa.biglobe.ne.jp
Conclusions Based on these results, we conclude that the Asian criterion of overweight appears to be rational in terms of its association with obesity-related metabolic disorders in male personnel of the Japan Self-Defense Forces in their fifties.

Keywords Diabetes - Dyslipidemia - Hypertension . Japanese $\cdot$ Overweight

\section{Introduction}

Obesity-related disorders occur at a much lower body mass index (BMI) in ethnic Asian populations than in ethnic Caucasian ones [1-6]. The Western Pacific Regional Office of the World Health Organization (WHO) has recommended lowering the BMI cutoff levels for Asian people to 23.0 for overweight and 25.0 for obesity [7]. The validity of the new criteria has been supported by several reports. For example, among ethnic Korean and Chinese populations, "overweight" subjects $\left(23.0-24.9 \mathrm{~kg} / \mathrm{m}^{2}\right)$ have been found to show a tendency toward an increased incidence of hypertension, dyslipidemia, and type 2 diabetes (Korean studies: [2, 4]; Chinese studies: [7-9]). Among ethnic Japanese, Shiwaku et al. [10] demonstrated the correlation between overweight and obesity-related metabolic parameters, including systolic blood pressure (SBP), cholesterol, triglycerides, and glucose. An association between the BMI category that is close to the Asian criterion and the presence of obesity-related disorders has also been shown in ethnic Japanese [11-15]. To date, however, very few studies have assessed the new criterion of overweight for Asian people (BMI of $23.0-24.9 \mathrm{~kg} / \mathrm{m}^{2}$ ) and the presence of obesity-related metabolic disorders among the Japanese $[6,10,15]$. 
In the study reported here, we analyzed the association between the Asian criterion of overweight and the presence of obesity-related disorders among middle-aged Japanese men. Age and lifestyle factors were adjusted for in the analysis model.

\section{Methods}

The study cohort consisted of middle-aged (age range 5159 years) male personnel of the Japan Self-Defense Forces (JSDFs) undergoing the retirement health check-up at the JSDFs' Central Hospital in 1999-2000. The BMI was calculated as $[(\text { weight, } \mathrm{kg}) /(\text { height, } \mathrm{m})]^{2}$. The participants were categorized as obese $\left(B M I \geq 25.0 \mathrm{~kg} / \mathrm{m}^{2}\right.$ ), overweight (BMI 23.0-23.9 kg/m ${ }^{2}$ ) and normal weight (BMI $<23.0 \mathrm{~kg} / \mathrm{m}^{2}$ ), according to the criteria for Asian people [7]. Information on lifestyle factors, including smoking habits, vegetable intake, ethanol consumption, physical activity [16], rank in the JSDFs, and present and past history of illness, were obtained using a self-completion questionnaire [17]. Vegetable intake was assessed by the self-rating scale and classified into four categories: poor intake, common intake, relatively rich intake, and rich intake. Each category of vegetable intake was given an ordinal number, and this was designated as the vegetable intake score. Average daily ethanol consumption rate was calculated from the type of beverage and daily consumption of each alcoholic beverage. Seniority in terms of rank in the JSDFs was categorized as previously reported [17].

Blood samples were collected after a 12-h overnight fast from an antecubital vein. Serum total cholesterol, triglycerides, uric acid and $\gamma$-glutamyl transferase were measured.

An oral $75 \mathrm{~g}$ glucose tolerance test was given after an overnight fast. Blood pressure was measured after resting in a sitting position using a mercury sphygmomanometer.

The diagnosis of diabetes and impaired glucose tolerance (IGT) was made according to the criteria of the WHO [18]. The diagnosis of hypertension was made based upon each individual's medical history or by the patient taking medication for hypertension $(\geq 140 / 90 \mathrm{mmHg}$ ) based on the criteria of the Seventh Report of Joint National Committee on Prevention, Detection, Evaluation, and Treatment of High Blood Pressure [19]. The diagnosis of hypercholesterolemia, hypertriglyceridemia, and hyperuricemia was based upon each individual's medical history and laboratory data: subjects with a total cholesterol level $>5.7 \mathrm{mmol} / \mathrm{L}(220 \mathrm{mg} / \mathrm{dL})$ were diagnosed with hypercholesterolemia, those with a triglyceride level $\geq 1.7 \mathrm{mmol} / \mathrm{L}(150 \mathrm{mg} / \mathrm{dL})$ were diagnosed with hypertriglyceridemia, those with a uric acid level $\geq 0.48 \mathrm{mmol} / \mathrm{L}$ $(8.0 \mathrm{mg} / \mathrm{dL})$ were diagnosed with hyperuricemia, and those with a $\gamma$-glutamyl transferase level $\geq 70$ IU/L were diagnosed with high $\gamma$-glutamyl transferase. The subjects gave informed consent. The study protocol was approved by the ethics committee of JSDFs' Central Hospital.

Descriptive data were expressed as the mean $\pm \mathrm{SD}$. Since the distribution of $\gamma$-glutamyl transferase was skewed, the analysis for $\gamma$-glutamyl transferase was carried out using the logarithm of $\gamma$-glutamyl transferase, and the results were transformed back to the original scale. Thus, geometric means were used for $\gamma$-glutamyl transferase. The 95\% confidence interval $(95 \% \mathrm{CI})$ of the geometric mean was found by taking the antilogarithm of the $95 \%$ CI of the logarithm of $\gamma$-glutamyl transferase. Mean values between multiple pairs of groups were compared by applying Fisher's protected least-significant difference (PLSD) post hoc test, if there was a significant difference in one-way analysis of variance (ANOVA). A logistic regression analysis was performed with metabolic disorder as the dependent variable. In an adjusted analysis model, age, daily number of cigarettes smoked, frequency of exercise strenuous enough to work up perspiration, daily ethanol consumption rate, and the rank in JSDFs were included as independent variables. The analyses were performed with the statistical program STATVIEW ver. 5.0 (SAS Institute, Carey, NC).

\section{Results}

Mean age was similar between the subjects with a normal body weight, those who were overweight, and those who were obese (Table 1). Mean (SD) BMI of the study population was $23.6(2.4) \mathrm{kg} / \mathrm{m}^{2}$. The prevalence rate of obesity and overweight was 28 and $32 \%$, respectively. No significant differences were observed between the three groups in terms of frequency of exercise strenuous enough to work up perspiration, vegetable intake, daily ethanol consumption, daily number of cigarettes smoked, or rank in the JSDFs.

Levels of fasting plasma glucose, 2-h plasma glucose (OGTT), SBP, total cholesterol, triglycerides, uric acid, and $\gamma$-glutamyl transferase were higher among overweight subjects than among normal weight subjects, respectively (Table 2).

Prevalence rates of metabolic diseases among the study population were $14.6 \%$ for type 2 diabetes, $22.6 \%$ for IGT, $20.9 \%$ for hypertension, $41.2 \%$ for hypercholesterolemia, $35.5 \%$ for hypertriglyceridemia, and $6.4 \%$ for hyperuricemia. Overweight subjects showed a higher prevalence rate of IGT, hypertension, hypercholesterolemia, hypertriglyceridemia, and hyperuricemia (Table 3). Prevalence rates of type 2 diabetes or high levels of $\gamma$-glutamyl transferase were not elevated among overweight subjects. Adjustment 
Table 1 Descriptive characteristics of normal body weight, overweight, and obese subjects of the Japan Self-Defence Forces (JSDFs)

\begin{tabular}{lllc}
\hline Lifestyle factors $^{\mathrm{a}}$ & \multicolumn{2}{l}{ Body mass index $\left(\mathrm{kg} / \mathrm{m}^{2}\right)$} & $\begin{array}{c}\text { ANOVA, } \\
P \text { values }\end{array}$ \\
\cline { 2 - 4 } & $\begin{array}{l}\text { Normal weight } \\
(<23.0 ; n=387)\end{array}$ & $\begin{array}{l}\text { Overweight } \\
(23.0-24.9 ; n=314)\end{array}$ & $\begin{array}{l}\text { Obese } \\
(\geq 25.0 ; n=273)\end{array}$ \\
\hline Age (years) & $52.8(0.9)$ & $53.0(1.0)$ & $53.0(1.1)$ \\
Body mass index $\left(\mathrm{kg} / \mathrm{m}^{2}\right)$ & $21.4(1.3)$ & $23.9(0.6)$ & $26.6(1.3)$ \\
Frequency of exercise enough to & $2.4(2.2)$ & $2.1(1.9)$ & $2.3(2.4)$ \\
$\quad$ work up perspiration (per week) & $36.5(30.9)$ & $35.5(30.1)$ & $33.4(31.9)$ \\
Ethanol consumption (mL/day) & $10.8(11.7)$ & $10.7(13.3)$ & $9.7(12.7)$ \\
Number of cigarettes smoked (no./day) & $2.7(0.8)$ & $2.7(0.8)$ & $2.6(0.8)$ \\
Vegetable intake score & $2.5(1.3)$ & $2.8(1.3) *$ & $2.6(1.3)$
\end{tabular}

$P$ values for normal weight subjects. Values given in parenthesis are the standard deviations

* $P=0.015$

${ }^{\text {a }}$ Ethanol consumption of abstainers was considered to be $0 \mathrm{~mL} /$ day; the number of cigarettes smoked by non-smokers was regarded to be $0 /$ day for the calculation of mean (SD) values

Table 2 Obesity, overweight, and metabolic parameters

\begin{tabular}{|c|c|c|c|c|}
\hline \multirow[t]{2}{*}{ Metabolic parameters } & \multicolumn{3}{|c|}{ Body mass index $\left(\mathrm{kg} / \mathrm{m}^{2}\right)$} & \multirow{2}{*}{$\begin{array}{l}\text { ANOVA, } \\
P \text { values }\end{array}$} \\
\hline & $\begin{array}{l}\text { Normal weight } \\
(<23.0 ; n=387)\end{array}$ & $\begin{array}{l}\text { Overweight } \\
(23.0-24.9 ; n=314)\end{array}$ & $\begin{array}{l}\text { Obese } \\
(\geq 25.0 ; n=273)\end{array}$ & \\
\hline Fasting plasma glucose $(\mathrm{mmol} / \mathrm{L})$ & $5.5(0.7)$ & $5.6(0.6)^{*}$ & $5.8(0.8)^{* *}$ & $<0.001$ \\
\hline 2-h Plasma glucose (mmol/L) & $7.0(2.9)$ & $7.5(2.4)^{*}$ & $8.4(2.9)^{* *}$ & $<0.001$ \\
\hline Systolic blood pressure (mmHg) & $118(12)$ & $122(31)^{* *}$ & $127(12)^{* *}$ & $<0.001$ \\
\hline Total cholesterol (mmol/L) & $5.3(0.9)$ & $5.7(0.8)^{* *}$ & $5.7(0.9)^{* *}$ & $<0.001$ \\
\hline Triglycerides (mmol/L) & $1.3(0.5)$ & $1.7(0.9)^{* *}$ & $2.0(1.2)^{* *}$ & $<0.001$ \\
\hline Uric acid (mmol/L) & $0.35(0.07)$ & $0.37(0.07)^{* *}$ & $0.39(0.07)^{* *}$ & $<0.001$ \\
\hline$\gamma$-Glutamyl transferase (IU/L) & 37 [18-76] & $42[21-83]^{*}$ & $50[27-92]^{* *}$ & $<0.001$ \\
\hline
\end{tabular}

$* P<0.05, * * P<0.001$ versus normal weight subjects

Subjects who were under medication were included in the analysis model

Values are given as the arithmetic mean, with the standard deviation given in parenthesis, with the exception of $\gamma$-glutamyl transferase for which the geometric mean is given with the $95 \%$ CI given in square parenthesis

for age, rank in JSDFs, and lifestyle factors little affected the results.

\section{Discussion}

The prevalence rates of obesity (28\%) and overweight (32\%) among the population studied (male, mean age 53 years) were similar to those reported for middle-aged civilian Japanese men (mean age 52 years) (32 and 24\%, respectively) [6]. Obesity-related metabolic disorders, including IGT, were more prevalent among the overweight subjects than among the normal weight ones (Table 3 ). To date, several published studies have reported an association between "overweight" and obesity-related metabolic disorders among the Japanese [11-15]. The results of the present reported here support these findings. To our best knowledge, this is the first report of an association between overweight and IGT among Japanese people.

Shiwaku et al. [10] reported that SBP and serum triglycerides are higher among overweight Japanese men (BMI 23.0-24.9 kg/m²) than those with a normal weight, which is consistent with our findings. In contrast, our results in terms of total cholesterol and fasting plasma glucose levels differed somewhat from those of Shiwaku et al. [10]. Total cholesterol and fasting glucose levels were not elevated among overweight men in their study, whereas they were elevated among the overweight men of our study. This apparent discrepancy may partly be explained by the difference in the age range of the study population [30-60 [10] vs. 51-59 years (present study)]. Since 
Table 3 Odds ratios of obesity and overweight for the presence of metabolic disorders

\begin{tabular}{|c|c|c|c|}
\hline \multirow[t]{2}{*}{ Metabolic disorders } & \multicolumn{3}{|c|}{ Body mass index $\left(\mathrm{kg} / \mathrm{m}^{2}\right)$} \\
\hline & $\begin{array}{l}\text { Normal weight } \\
(<23.0 ; n=387)\end{array}$ & $\begin{array}{l}\text { Overweight } \\
(23.0-24.9 ; n=314)\end{array}$ & $\begin{array}{l}\text { Obese } \\
(\geq 25.0 ; n=273)\end{array}$ \\
\hline \multirow[t]{3}{*}{ Type 2 diabetes } & 1.0 & $1.09(0.67-1.76)$ & $2.82(1.84-4.33)$ \\
\hline & {$[1.0]$} & {$[1.16(0.71-1.88)]$} & [2.90 (1.88-4.48)] \\
\hline & $<10.3>$ & $<11.1>$ & $<24.5>$ \\
\hline \multirow[t]{3}{*}{ Impaired glucose tolerance } & 1.0 & $1.61(1.11-2.33)$ & $1.98(1.36-2.88)$ \\
\hline & {$[1.0]$} & {$[1.57(1.08-2.28)]$} & [1.93 (1.32-2.81)] \\
\hline & $<16.8>$ & $<24.5>$ & $<28.6>$ \\
\hline \multirow[t]{3}{*}{ Hypertension } & 1.0 & $1.95(1.30-2.93)$ & $3.36(2.26-4.82)$ \\
\hline & {$[1.0]$} & [1.99 (1.32-2.98)] & [3.42 (2.30-5.09)] \\
\hline & $<12.4>$ & $<21.7>$ & $<32.2>$ \\
\hline \multirow[t]{3}{*}{ Hypercholesterolemia } & 1.0 & $2.22(1.63-3.03)$ & $2.10(1.52-2.89)$ \\
\hline & {$[1.0]$} & {$[2.25(1.65-3.08)]$} & [2.15 (1.55-2.97)] \\
\hline & $<30.2>$ & $<49.0>$ & $<47.6>$ \\
\hline \multirow[t]{3}{*}{ Hypertriglyceridemia } & 1.0 & $2.83(2.02-3.97)$ & $4.40(3.12-6.22)$ \\
\hline & {$[1.0]$} & {$[2.83(2.01-3.98)]$} & [4.64 (3.26-6.60)] \\
\hline & $<19.6>$ & $<40.9>$ & $<51.8>$ \\
\hline \multirow[t]{3}{*}{ Hyperuricemia } & 1.0 & $2.06(1.06-4.00)$ & $2.29(1.17-4.48)$ \\
\hline & {$[1.0]$} & {$[2.07(1.06-4.04)]$} & [2.30 (1.17-4.53)] \\
\hline & $<3.9>$ & $<7.7>$ & $<8.5>$ \\
\hline \multirow[t]{3}{*}{ High $\gamma$-glutamyl transferase ${ }^{a}$} & 1.0 & $1.05(0.71-1.56)$ & $1.88(1.29-2.73)$ \\
\hline & {$[1.0]$} & {$[1.11(0.73-1.68)]$} & [2.19 (1.47-3.26)] \\
\hline & $<16.8>$ & $<17.5>$ & $<27.5>$ \\
\hline
\end{tabular}

Values are given as odd ratios; round parentheses indicate the 95\% confidence interval; square parentheses indicate the odds ratios adjusted for age, frequency of exercise enough to work up perspiration, daily number of cigarettes smoked, daily ethanol consumption rate, vegetable intake, and rank; $<>$, prevalence rate of metabolic disorder, in percentage

a $\geq 70 \mathrm{IU} / \mathrm{L}$ uricemia, but not those of diabetes or high $\gamma$-glutamyl transferase.

\section{References}

1. Deurenberg-Yap M, Chew SK, Deurenberg P. Elevated body fat percentage and cardiovascular risks at low body mass index levels among Singaporean Chinese, Malays and Indians. Obes Rev. 2002;3:209-15.

2. Moon OR, Kim NS, Jang SM, Yoon TH, Kim SO. The relationship between body mass index and the prevalence of obesityrelated diseases based on the 1995 National Health Interview Survey in Korea. Obes Rev. 2002;3:191-6.

3. Lin W-Y, Lee L-T, Chen C-Y, Lo H, Hsia H-H, Liu I-L, et al. Optimal cut-off values for obesity: using simple anthropometric indices to predict cardiovascular risk factors in Taiwan. Int $\mathbf{J}$ Obes. 2002;26:1232-8.

4. Kim Y, Suh YK, Choi H. BMI and metabolic disorders in South Korea adults: 1998 Korean National Health and Nutritional Survey. Obes Res. 2004;12:445-53.

5. Kanazawa M, Yoshiike N, Osaka T, Numba T, Zimmet P, Inoue S. Criteria and classification of obesity in Japan and Asia-Oceania. Asia Pacific J Clin Nutr. 2002;11[Suppl]:S732-7.

6. Anuurad E. The new criteria for Asians by the regional office for the Western Pacific Region of WHO are suitable for screening of overweight to prevent metabolic syndrome in elder Japanese workers. J Occup Health. 2003;45:335-43.

7. World Health Organization. Western Pacific Region, International Association for the Study of Obesity. The Asia-Pacific people showed higher prevalence rates of hypertension, hypercholesterolemia, hypertriglyceridemia, and hyper- 
Perspective. Redefining Obesity and its Treatment. Sydney: Health Communications Australia, 2000.

8. Ko GT, Chan JC, Cockram CS, Woo J. Prediction of hypertension, diabetes, dyslipidemia or albuminuria using simple anthropometric indexes in Hong Kong Chinese. Int J Obes Relat Metab Disord. 1999;23:1136-42.

9. Deurenberg-Yap M, Yan TB, Kai CS, Deurenberg P, van Staveren WA. Manifestation of cardiovascular risk factors at low levels of body mass index and waist-to hip ration in Singaporean Chinese. Asia Pacific J Clin Nutr. 1999;8:177-83.

10. Shiwaku K, Anuurad E, Enkhmaa B, Nogi A, Kitajima K, Shimono K, et al. Overweight Japanese with body mass indexes of 23.0-24.9 have higher risks for obesity-related disorders: a comparison of Japanese and Mongolians. Int J Obes Relat Metab Disord. 2004;28:152-8.

11. The Examination Committee of Criteria for 'Obesity Disease' in Japan. Japan Society for the Study of Obesity. New criteria for 'obesity disease' in Japan. Circ J 2002;66:987-92.

12. Yoshiike N, Nishi N, Matsushima M, Ito C, Ikeda Y, Kashihara $\mathrm{H}$, et al. Relation between body mass index and risk for diabetes, hypertension, hyperlipidemia - an epidemiological study by multicenter cooperative study (In Japanese). J Jpn Soc Study Obes 2000;6:4-17.

13. Tokunaga K, Matsunaga Y, Kotani K, Keno Y, Kobatake T, Fujioka S, et al. Ideal body weight estimated from the body mass index with the lowest morbidity. Int J Obes. 1991;15:1-5.
14. Shiwaku K, Anuurad E, Enkhmaa B, Nogi A, Kitajima K, Yamasaki $\mathrm{M}$, et al. Predictive values of anthropometric measurements for multiple metabolic disorders in Asian populations. Diab Res Clin Pract. 2005;69:52-62.

15. Yang J-J, Shiwaku K, Nabika T, Masuda J, Kobayashi S. High frequency of cardiovascular risk factors in overweight adult Japanese subjects. Arch Med Res. 2007;38:337-44.

16. Manson JE, Nathan DM, Krdewski AS, Stampfer MJ, Willett WC, Hennekens $\mathrm{CH}$. A prospective study of exercise and incidence of diabetes among US male physicians. J Am Med Assoc. 1992;268:63-7.

17. Sakuta H, Suzuki T. Rank in Self-Defense Forces and risk factors for atherosclerotic disease. Mil Med. 2005;170:820-4.

18. WHO Consultation. Definition, diagnosis and classification of diabetes mellitus and its complications. Part 1: Diagnosis and classification of diabetes mellitus. 1999; Geneva, Switzerland, World Health Organization.

19. Chobanian AV, Bakris GL, Black HR, Cushman WL, Green LA, Izzo JL Jr, et al. National Heart, Lung, and Blood Institute Joint National Committee on prevention, detection, evaluation, and treatment of high blood pressure; National High Blood Pressure Program Coordinating Committee; The seventh Report of the Joint National Committee on Prevention, Detection, Evaluation, and Treatment of High Blood Pressure: the JNC 7 report. J Am Med Assoc. 2003;289:2560-72. 